\title{
Change in testosterone concentrations over time is a better predictor than the actual concentrations for symptoms of late onset hypogonadism
}

\author{
Anna-Clara Spetz, Mats Fredrikson, Elvar Theodorsson, Lennart G Palmefors, \\ Per S Karlsson, Charlotte Joborn and Mats Hammar
}

\section{Linköping University Post Print}

N.B.: When citing this work, cite the original article.

Original Publication:

Anna-Clara Spetz, Mats Fredrikson, Elvar Theodorsson, Lennart G Palmefors, Per S Karlsson, Charlotte Joborn and Mats Hammar, Change in testosterone concentrations over time is a better predictor than the actual concentrations for symptoms of late onset hypogonadism, 2011, The Aging Male, (14), 4, 249-256.

http://dx.doi.org/10.3109/13685538.2011.582527

Copyright: Informa Healthcare http://informahealthcare.com/

Postprint available at: Linköping University Electronic Press http://urn.kb.se/resolve?urn=urn:nbn:se:liu:diva-72806 


\title{
Change in testosterone concentrations over time is
}

\author{
a better predictor than the actual
}

\section{concentrations for symptoms of}

\section{Late Onset Hypogonadism.}

Anna-Clara E Spetz Holm, MD, PhD, Mats G Fredrikson,* PhD, Elvar Theodorsson, MD, PhD**, Lennart G Palmefors, MD, Per S Karlsson, MD, Charlotte Joborn, MD, and Mats L Hammar, MD, $\mathrm{PhD}$.

Division of Obstetrics and Gynecology, Department of Clinical and Experimental Medicine, Faculty of Health Sciences, Linköping University, Department of Obstetrics and Gynecology in Linköping, County Council of Östergötland, Linköping, Sweden

*Division of Occupational and Environmental Medicine, Department of Clinical and Experimental Medicine, Faculty of Health Sciences, Linköping University, Department of Occupational and Environmental Medicine in Linköping, County Council of Östergötland, Linköping, Sweden

**Division of Clinical Chemistry, Department of Clinical and Experimental Medicine, Faculty of Health Sciences, Linköping University, Department of Clinical Chemistry, County Council of Östergötland, Linköping, Sweden

Short title: Testosterone and $\mathrm{LOH}$

Key words: men; andrology; climacteric; questionnaires; testosterone; androgens

Reprint requests and correspondence:

Anna-Clara Spetz Holm, Department of Clinical and Experimental Medicine, Obstetrics and Gynecology, Faculty of Health Sciences, University Hospital, S-581 85 Linköping, Sweden. e-mail: Anna-Clara.Spetz.Holm@LiO.se Phone: +46 101033130, Fax: +4613148156 


\section{ABSTRACT}

Symptoms of Late onset Hypogonadism (LOH) and concentrations of Testosterone (T) and Bioavailable Testosterone (BT) were studied in relation to the data from the same men five years earlier.

Methods: In 2008, 282 men, 60-82 years answered a questionnaire regarding demographic data, medical history, different symptoms of $\mathrm{LOH}$ and the 10 questions from the "ADAM-questionnaire". Blood samples were analysed for concentrations of $\mathrm{T}$ and calculations were made for BT. Results: $87.2 \%$ of the questionnaires were returned and analysed, and $75.2 \%$ of the responders gave blood samples. The oldest third of the men were most affected by LOH symptoms $(\mathrm{p}<0.05)$. Both T and BT-concentrations decreased during the five years $(\mathrm{p}<0.05)$ but only the symptom "less strong erections" changed significantly $(\mathrm{p}<0.05)$. Men reporting one of four specific symptoms from the “ADAM-questionnaire" for the first time in 2008 had a higher loss of T and BT than men who had unchanged or fewer symptoms than reported in 2003.

Conclusions: The magnitude of the decrease in concentrations is a better predictor of LOH than are the actual concentrations of $\mathrm{T}$ and or BT. A combination of symptoms predicts LOH better than any single symptom. 


\section{INTRODUCTION}

Late onset Hypogonadism (LOH) [1] also sometimes called Partial Androgen Decline in Aging Males (PADAM) or Androgen Decline in Aging Males (ADAM) [2] describes the gradual decline in androgen production in men, sometimes accompanied by a number of rather subtle symptoms including gradual loss of muscle strength and bone density, decrease in libido, memory, enjoyment of life and mood, as well as impotence, asthenia and cognitive dysfunctions [3-5]. Recognition of LOH is frequently obscured by signs of natural ageing enhanced by "male climacteric" factors.

The production of testicular testosterone gradually decreases with age in men but this decrease is more individually variable [6] and is not as readily evident or abrupt as the estrogen decrease seen in women during the climacteric period. In normally aging men, total testosterone and albumin-bound testosterone concentrations in serum decline, whereas sex hormone binding globulin usually increases [7]. This leads to a more readily observable decrease in circulating free or bio-available testosterone (BT) than in total testosterone (T) [6].

In a cross-sectional Swedish study performed in 2003, we investigated probable symptoms of LOH and associated them with hormone concentrations [8]. We found that symptoms associated with LOH often occur in an elderly population, but that only three symptoms were associated with low blood testosterone concentrations: "deterioration in work performance, decreased strength and bothersome hot flushes". Also in line with previous reports [9], 4.5\% of men reported hot flushes, which is why we suggest that hot flushes should be regarded as a possible LOH symptom. There are also other studies $[10,11]$ that have failed to identify a connection between LOH symptoms and circulating androgen levels. To monitor changes in LOH symptoms as well as androgens, we used the same cross-sectional study design as in 2003 in the same cohort of men but five years later.

The objectives of this study were; 
1) to assess the prevalence of different symptoms associated with $\mathrm{LOH}$ including hot flushes and to correlate these symptoms with sex steroid concentrations, and

2) to compare the results with the results from the study performed 5 years earlier [8] and to assess by means of a questionnaire whether changes in sex steroid (T and BT) concentrations were associated with certain symptoms. 


\section{METHODS}

This is a longitudinal study comparing the results from year 2003 to 2008 . A questionnaire was sent to 370 men in 2003 (chosen by means of a computer-generated randomisation list), age 55 to 75 who were registered at three different Primary Health Care Centres in south-east Sweden [8]. Of the 302 men who had received and returned questionnaires that were analysed in 2003 [8], 282 men were sent questionnaires again in early 2008 . We were unable to find twenty men in the national population registry by February 2008, which means that they had either died or moved abroad. The questionnaire included questions about demographic data, marital status, medical history, mood disorders, ongoing medication including hormone therapy, alcohol, smoking, exercise habits etc. The men were asked about current hot flushes, as well as the extent to which they were bothered by them, tiredness, muscular/skeletal pain, balance, frailty fractures, decreased libido, decreased energy and changes in muscular strength/endurance among other questions. The question about hot flushes asked if the subject experienced a sudden and unexpected feeling of warmth or sweating unrelated to being in a warm environment or doing physical work. The men were offered the chance to have a blood-test for analyses of T, Albumin, Sex Steroid Hormone Binding Globulin (SHBG) and Albumin. Blood-samples were drawn at the Primary Health Care Centres. Body Mass Index (BMI) was calculated for each individual by reported length and weight from the questionnaire.

The questionnaire was designed to make it as easy as possible for the subjects to answer so that all that had to be done was to make a tick mark in the series of boxes. The questionnaire was slightly modified from a previously used and validated questionnaire developed by us $[9,12]$. Reproducibility was tested by Spetz et al. 2007 [8].

\section{The ADAM-questionnaire}

Morley et al. have validated the use of the ADAM-questionnaire, as a means of screening for individuals with possible low levels of BT $[13,14]$. The 10 questions from the ADAM-questionnaire were translated into Swedish and scattered throughout the questionnaire. According to Morley and coworkers, answering "yes" to item 1 or 7 or "yes" to any other three questions predicts low BT with a sensitivity of $88 \%$ and a specificity of $60 \%$ [14]. We chose, however, to create an additional score; “ADAM-positivity and -negativity”, where men positive for the ADAM-questionnaire (answering 
"yes" to item 1 or 7 or "yes" to any other three questions or more) were classified as "ADAM-positive", and the others were "ADAM-negative" [8]. We also developed a term called "ADAM-sum", according to the number of "yes" replies in the questionnaire. One to three "yes" is called "low ADAM-sum", four to six "yes" is called "medium ADAM-sum" and seven to ten "yes" "high ADAM-sum", i.e. we did not give the answers to questions 1 or 7 any special attention [8].

\section{Data handling}

The questionnaires were coded only in order to be able send a reminder to the subjects. All information from the answered questionnaires was optically scanned and exported to SPSS for Windows. The agreement between optical and manual reading was checked for the first ten complete questionnaires and the optical reading was continued only after the manual and the optical reading agreed totally. All information was handled confidentially. All data were analysed by using SPSS 14.0, (SPSS Inc, Chicago, Ill, USA) except for the regression analyses for BMI and BT, where STATA 9.2, (College Station, Tx, USA) was used. To test the differences between age-groups we used Pearsons $\chi^{2}$ and $\mathrm{p}<0.05$ was considered as significant. ANOVA-, Bonferroni-, and Students T-test were used when appropriate to find differences between grades of symptoms/single symptom and BT and T, respectively. Regression analyses were used to investigate if any associations were found between different symptoms and BT and T. McNemars $\chi^{2}$ was used to test the difference between ADAM categories from 2003 to 2008 .

\section{Laboratory investigations:}

Fed morning serum samples from 329 of the 370 men (all centers except for one of the Primary Health Centre) were analysed as follows. Albumin was analysed using Immunochemistry (Advia 1800, Siemens Medical Solutions Diagnostics, Sweden). Testosterone and SHBG were measured using timeresolved fluorometry immunoassay AutoDelfia 1235, Perkin Elmer Life and Analytical Science, Sweden). Almost all analyses were made at the department of Clinical Chemistry, University Hospital, Linkoping, Sweden using the same methods as in 2003 [8].

Fed morning serum samples from 41 men from one of the three different Primary Health Care Centres, were analysed as follows. Albumin was measured using a spectrophotometric bromcresolgreen-method 
(BCG) (J\&J Vitros ECI, Ortho Clinical Diagnostics), Testosterone and SHBG were analysed by chemoluminiscence immunoassay (Immulite 2500, Siemens Medical Solutions Diagnostics, Sweden). To eliminate inter- laboratory/inter method bias, weighted linear recalibration equations were established between the methods using natural patient samples covering the full concentration range of the present study. Albumin; $y=0.9 x+8.9, r 2=0.96, n=30 ;$ Testosterone; $y=0.9 x+0,1 ; r 2=0.95, n=46$ and SHBG; $y=0.8 x+1.3, r 2=0.99, n=48)$. These recalibration equations were used to convert the concentrations measured in the samples from the 41 men to be equivalent to be equivalent to the concentrations in the remaining 329 men.

The within $[\mathrm{CVw}(\%)]$ - and between days $[\mathrm{CVb}(\%)]$ coefficients of variation for control samples having concentrations in the range encountered in the study were as follows: Albumin Advia 1800, 4.2 and 4.3, Testosterone AutoDelfia 4.8 and 5.0, SHBG AutoDelfia 4.6 and 5.4 Albumin Vitros 3.9 and 4.0, Testosterone Immulite 25005.9 and 6.2 and SHBG Immulite 25006.4 and 6.2.

BT was calculated based on concentrations of Testosterone, Albumin, and SHBG according to an algorithm previously described [15].

\section{Ethics}

All data were handled confidentially. The study was approved by the Regional Ethical Committee at the Faculty of Health Sciences, Linkoping University. 


\section{RESULTS}

In total 282 questionnaires were sent out. After one reminder, 249 questionnaires were returned, three of which were not filled in, making 246 questionnaires (87.2\%) eligible for evaluation. Thirteen men had been treated by castration, but their questionnaires were not excluded from analyses since their answers did not differ much from the "average-answered" questionnaires. The median age of the men was 68.4 years (YY) (range 60-82 YY; SD 5.73YY). We split the men into three different age groups, the same men in each group as in 2003. Demographic data are presented in table I.

Ninety-six men (54\% ) used medication for hypertension and/or cardiac disease. Thirty-nine men used a low dose of acetylsalicylic acid, twelve men used warfarin and 45 men used blood-lipid-lowering medication. Psychoactive drugs, e.g. selective serotonin reuptake inhibitors (SSRI) and serotonin and norepinephrine reuptake inhibitors (SNRI) were used by seven men whereas none used benzodiazepines. Sleeping pills were used by five men. Six men used chronic medication for painrelief. Other medications $(\mathrm{n} \leq 4)$ included insulin, oral antidiabetic medication, medication for asthma or allergy, constipation and epilepsy, metotrexate and antiandrogens (bicalutamide). One man used Testosterone gel.

\section{Laboratory tests and correlations}

Laboratory tests were obtained from 185 men, $75.2 \%$ of men answering the questionnaire (Figure 1). Changes of BT and T between 2003 and 2008 are shown in Figure 1.

There was no significant difference between levels of BT and $\mathrm{T}$ according to reported alcoholic intake or between smokers and non-smokers.

\section{Exercise habits and the muscular/skeletal system}

Type and frequency of exercise habits are presented in Table I. Men who exercised > $12 \mathrm{~h} / \mathrm{month}$ (74.4\%) had higher concentrations of $\mathrm{T}$ (mean $15.4 \mathrm{nmol} / \mathrm{L})$ than those who exercised less $(\mathrm{T}=12.9$ $\mathrm{nmol} / \mathrm{L} ; \mathrm{p}=0.0291$ ), whereas BT did not differ between these groups.

\section{The ADAM-questionnaire and other possible symptoms of $\mathrm{LOH}$}

Five of the symptoms listed in the ADAM-questionnaire were more common in the older age groups than in the younger/youngest; i.e. "decrease in libido", "lack of energy", "decreased strength and/or 
endurance", "less strong erections" and "deterioration in work performance" $(p<0.05)$. Three of ten symptoms were associated with low BT and T (Table II). In the youngest age group, $\mathrm{T}$ was lower in men who reported decreased enjoyment of life and in men who reported sadness and/or grumpiness than in men who did not express these complaints ( $\mathrm{p}=0.017$ and 0.025 , respectively). None of the other symptoms from the ADAM-questionnaire were significantly connected with low concentrations of T and BT.

Medication to deal with problems experienced during intercourse was tried by $11.2 \%$ of the men showing no differences between age-groups. "Decreased need to shave" was more commonly reported by the oldest men than by men in age group II $(\mathrm{p}<0.001)$.

$83.7 \%$ of all men were "ADAM-positive", significantly more in the older age-groups than in the youngest ( $\mathrm{p}<0.05)$. "ADAM-positive" men had lower T and BT than "ADAM-negative" men $(\mathrm{p}=0.003$ and 0.023 respectively), whereas SHBG did not differ. Men with "low ADAM-sum" had higher T and BT than men with higher "ADAM-sum" (Figure 2). ADAM-sum was lower in the youngest age-group than in the others ( $\mathrm{p}=0.001$ ). $54.4 \%$ in the youngest group and $29.1 \%$ and $26.7 \%$ in the older agegroups had "low ADAM-sum". A high ADAM-sum was more common in age-groups II and III, (27.9\% and $22.7 \%)$ than in the youngest age group $(\mathrm{p}=0.00)$.

\section{Hot flushes}

$3.7 \%$ of men reported hot flushes at least a few times weekly. In total, $26.9 \%$ reported hot flushes. Of men reporting hot flushes $54 \%$ were bothered by them, and $18 \%$ suffered moderately to severely. There was no difference between $\mathrm{T}$ and BT concentrations either between age groups or between men who reported and/or suffered from hot flushes and those who did not.

There was no significant difference in the prevalence of hot flushes between those men who exercised more than 12 hours per month and those who exercised less or between men who used alcohol once a week and men who used alcohol once a month or less. Hot flushes were more prevalent in men who used psychoactive drugs, e.g. sleeping pills (5 men), SSRI/SNRI (7 men) than in non-users (62.6\% compared to $12.6 \% ; \mathrm{p}<0.0001$ ) and also suffering from them was also more prevalent in men who used psychoactive drugs (36.8\% and $12.9 \%$, respectively, $\mathrm{p}=0.009)$. $\mathrm{T}$ and BT concentrations did not differ between these two groups. 
Changes in symptoms and hormones between 2003 and 2008

BT-, T- and albumin-concentrations decreased and SHBG-concentrations increased significantly over 5 years (Figure 1, $\mathrm{p}<0.05)$. Men who were diagnosed with prostate cancer between 2003 and $2008(\mathrm{n}=10)$ did not have T- or BT-concentrations in 2003 that differed from T- or BT-concentrations in the rest of the study-population in 2003. A study of single symptoms showed that only one was reported significantly more or less often in 2008 than 2003; i.e. 39 more men ( $n=144$ in 2008) reported less strong erections $(\mathrm{p}=0.0003)$.

According to the "ADAM sum", for every increased step in this 10-grade scale, i.e. one more symptom from the ADAM-questionnaire in 2008 added since 2003, BT levels decreased by $0.30 \mathrm{nmol} / \mathrm{L}$ and T decreased by $1.62 \mathrm{nmol} / \mathrm{L}(\mathrm{p}=0.004$ and 0.001$)$.

There was no significant difference in the number of "ADAM-positive" and "ADAM-negative" men between year 2003 and 2008.

For four of the ten symptoms in the ADAM-questionnaire, there were higher losses of BT and/or T concentrations in men reporting the specific symptom for the first time in 2008 than in men who reported the same or fewer symptoms since $2003(\mathrm{p}<0.05)$ (Table III).

\section{DISCUSSION}

As in the former study [8] BT- and T-concentrations did not differ between age-groups. However, as expected, a comparison of the hormonal concentrations reported in 2003 and 2008 showed that T- and BT-concentrations diminished in all age-groups and SHBG increased $(\mathrm{p}<0.05)$. Surprisingly only one single symptom from the questionnaire was more prevalent in 2008 , i.e. "less strong erections" and only a few single symptoms were associated with low BT and/or T. However, when the symptoms were combined in groups, "ADAM-sum" changed from 2003 to 2008 [8]; i.e. for every new symptom added since 2003, BT- and T-concentrations diminished. Also, men with low “ADAM-sum” (low symptom burden) had higher concentrations of BT and/or T than men with medium and high "ADAM-sum in both studies [8]. 84\% of the men were "ADAM-positive", more in the oldest age-group than in the others. The same was reported in 2003 (85\%) [8]. However, in the current study we also found that 
"ADAM-positive" men had lower BT- and T-concentrations, supporting the results from Morley et al [14].

Interestingly, we found higher loss of BT and/or T concentrations over five years in men reporting some specific symptoms for the first time in 2008 than in men who reported the same or fewer symptoms in 2008 than in 2003. We interpret this as a change in BT and $\mathrm{T}$ is a better predictor of symptom development than the actual level of T or BT. It must be kept in mind, however, that there are many factors other than low testosterone that can cause almost the same symptoms. As discussed by Wang et al [1], it is difficult to diagnose LOH since many of the symptoms indicating $\mathrm{LOH}$ can occur in connection with other diseases and as a result of ageing alone.

Hot flushes were reported by more than every fourth man, and half of them said that they suffered from the flushes. This is in line with our earlier studies on aging men [8,9]. However, flushes occurring more often than once a week are still reported only by a minority, $3.7 \%$ in this report, and $4.5 \%$ in the former study [8]. We have previously suggested that hot flushes should be considered for incorporation in the set of symptoms of LOH [8], because hot flushes are common in men and women deprived of sex steroids, i.e. men treated by castration due to prostate cancer and menopausal women $[18,19]$. The clinical entities LOH, PADAM, and "andropause" are still controversial. McKinley et al [16] asked for a "decent burial" of this controversy, since they stated that the issue has been repeatedly examined and shows little evidence of life. It is well known that testosterone concentrations decrease with age in healthy aging men, but still there are men that keep their testosterone production almost intact throughout their lifespan and who are reproductive even in old age [17]. However, most men have decreasing testosterone production as a consequence of testicular failure and low activity in the gonadal-hypophyseal-hypothalamic axis, some with symptoms of LOH and some without. Unfortunately, due to technical problems at one of the primary health care centres, blood samples from 41 men were not sent for analyses to the department of Clinical Chemistry, University Hospital of Linkoping, but instead were analysed at the local Clinical Chemistry laboratory using other methods. However, between 30 and 48 natural patient samples were analysed by both methods and used to re-calibrate and re-calculate the results from these 41 samples in the study in a reliable manner. 
The response rate of $87 \%$ is very satisfying for this kind of study. The men were, in addition to being offered contact with their doctor, also informed of the results from the study in 2003, which may have made them more prone to answer the questionnaire once again.

In the current study three of ten symptoms, from the ADAM-questionnaire; "lack of energy", deterioration of work-performance" and "decreased strength and/or endurance", were associated with lower T- and BT-concentrations. However, when comparing the decrease of BT- and T-concentrations from 2003 to 2008 with symptoms reported for the first time in 2008, four of ten symptoms in the ADAM-questionnaire were associated with a more pronounced decrease of BT and/or T concentrations in men who reported changes in the specific symptom or relief of the symptom than men who reported no changes in the specific symptom or relief of symptom since 2003 [8] $(\mathrm{p}<0.05)$ (Table III). One of these symptoms was "loss in libido". Also "less strong erections", "lack of energy" and "deterioration in work-performance" showed the same tendencies, the first two symptoms seen to be associated with a low serum testosterone level may raise suspicion of testosterone deficiency, according to Wang et al [1].

One interesting question was whether men diagnosed with prostate cancer after the study from 2003 [8], might have had higher T- or BT-concentrations than the other men in the study from 2003 . We were, however, not able to confirm this.

The clinical entity LOH is still controversial, since it is very difficult to sort out if it is age per se or the partial androgen insufficiency that gives rise to the different symptoms associated with the entity $[1,20,21]$. This study did not find any strong correlation between LOH symptoms and circulating testosterone concentrations. Others have previously attempted to create symptom scores based on answers to questionnaires, for example the ADAM [14] questionnaire and the Aging Male Survey, that are highly sensitive, but nevertheless have suboptimal specificity. Recently, Morley suggested that a combination of symptoms and testosterone measurement is inadequate to make the diagnosis of LOH. According to him the diagnosis can only be stated when there are symptoms, low testosterone and amelioration of symptoms within a three months period of testosterone therapy [22]. Wang et al [1], recommend a structured scheme built on evidence and grades and stated that low libido is the most common symptom associated with LOH [1]. In this study, many symptoms were reported to be more 
frequent in the older age groups, but only a few of them were associated with decrease hormonal concentrations. However, analysis of the decrease in BT and T- concentrations from 2003 to 2008 showed that a few symptoms, including low libido and less strong erections were more common, suggesting that the changes in the $\mathrm{T}$ - and $\mathrm{BT}$-concentrations over the years might be more important than the actual concentration measured at the specific moment. It also became evident that a combination of different symptoms seems to predict the suspicion of LOH better than single symptoms. In conclusion, we were not able to find a new, more easily useable instrument to identify $\mathrm{LOH}$, even though using a complex of suggested symptoms seems to be more reliable than using any single symptom. However, we believe that it is the magnitude of the loss, rather than the actually measured concentrations of $\mathrm{T}$ and or BT, that seems to be more crucial in indicating the occurrence of symptoms of $\mathrm{LOH}$. The LOH-entity is very complex and every patient has to be taken care of individually with special care being given to the individual patient's medical history and lifestyle.

\section{ACKNOWLEDGEMENTS:}

We are indebted to the Swedish Medical Research Council, grant no K2000-72X-12651-04B and the Medical Research Council of Southeast Sweden.

\section{DECLARATION OF INTEREST STATEMENT}

The authors report no declarations of interest. 


\section{REFERENCES}

1) Wang C, Nieschlag E, Swerdloff R, Behre HM, Hellstrom WJ, Gooren LJ, Kaufman JF, Legros JJ, Lunenfeld B, Morales A, Morley JE, Schulman C, Thompson IM, Weidner W, Wu FC. ISA, ISSAM, EUA, EAA, and ASA recommendations: investigation, treatment, and monitoring of late-onset hypogonadism in males. Aging Male 2009;12:5-12.

2) Morales A, Heaton JP, Carson CC III. Andropause: a misnomer for a true clinical entity. J Urol 2000;163:705-712.

3) Lunenfeld B, Nieschlag E. Testosterone therapy in the aging male. Aging Male 2007;10:139-153:

4) Moncada I. Testosterone and men's quality of life. Aging Male Jan 2006;9:189-193.

5) Morley JE. Should frailty be treated with testosterone? Aging Male Mar 2011;14:1-3.

6) Nahoul K, Roger M. Age-related decline of plasma bioavailable testosterone in adult men. J Steroid Biochem 1990;35:293-299.

7) Gray A, Feldman HA, McKinlay JB, Longcope C. Age, disease, and changing sex hormone levels in middle-aged men: results of the Massachusetts male aging study. J Clin Endocrinol Metab 1991;73:1016-1025.

8) Spetz AC, Palmefors L, Skobe S, Strömstedt M, Fredriksson M, Theodorsson E, Mats Hammar. Testosterone correlated to symptoms of "Partial Androgen Deficiency in Aging Men" (PADAM) in a Swedish elderly population. Menopause 2007;14:999-1005. 
9) Spetz AC, Fredrikson MG, Hammar ML. Hot flushes in a male population aged 55, 65, and 75 years, living in the community of Linkoping, Sweden. Menopause 2003;10:81-87.

10) Hanus M, Matouskova M, Starka L, Hill M. Hormonal homeostasis in a group of 216 Czech males and correlation with responses to a questionnaire of the University of St Louis. Aging Male 2006;9:103-110.

11) T’Sjoen G, Goemaere S, De Meyere M, Kaufman J. Perception of males`aging symptoms, health and well-being in elderly community-dwelling men is not related to circulating androgen levels. Psychoneuroendocrinology 2004;29:201-214.

12) Gladh M, Rahgozar M, Hammar M, Fredriksson M, Spetz A-C. Prevalence of symptoms possibly related to PADAM, in a Swedish population aged 55, 65 and 75 years. Maturitas 2005;50:161-166.

13) Morley JE. Sex hormones and diabetes. Diabetes Metab Rev 1998;6:6-15.

14) Morley JE, Charlton E, Patrick P, Kaiser FE, Cadeau P, McCready D, Perry HM $3^{\text {rd }}$. Validation of a screening questionnaire for androgen deficiency in aging males. Metabolism 2000;49:1239-1242.

15) Vermeulen A. The physical state of testosterone in plasma. In: V. H. T. James V. H. T. et al, editors. The Endocrine Function of the Human Testes. New York: Academic Press; 1973. p. 157-170.

16) McKinlay JB, Travison TG, Araujo AB, Kupelian V. Editorial. Male menopause---time for a decent burial? Menopause 2007;14:973-975.

17) Sartorius GA, Nieschlag E. Paternal age and reproduction. Hum Reprod Update 2010;16:65-79. 
18) Hammar M, Berg G, Fåhraeus L, Larsson-Cohn U. Climacteric symptoms in an unselected sample of Swedish women. Maturitas 1984;6:345-350.

19) Karling P, Hammar M, Varenhorst E. Prevalence and duration of hot flushes after surgical or medical castration in men with prostatic carcinoma. J Urol 1994;152:1170-1173.

20) Gould DC, Petty R, Jacobs HS. For and against: The male menopause-does it exist? BMJ 2000;320:858-861

21) Schow DA, Redmon B, Pryor JL. Male menopause. How to define it, how to treat it. Postgrad Med 1997;101:62-64,67-68,71-74.

22) Morley JE. The diagnosis of late life hypogonadism. The Aging Male 2007;10:217-220

Figure 1
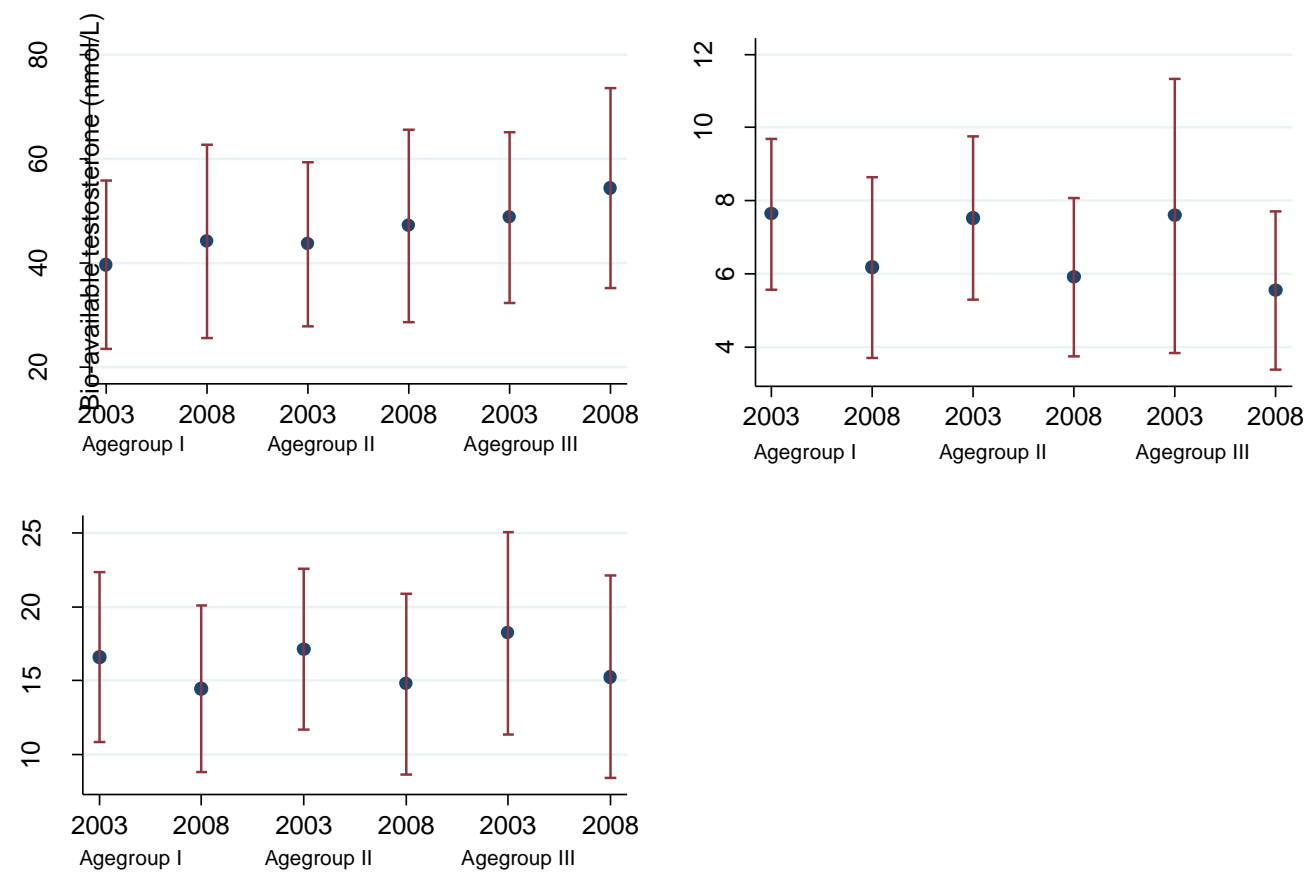

- Mean value Standard deviation 
Figure 1: Measurements of hormones and changes in hormonal concentrations between year 2003 and 2008.

Significant changes $(p \leq 0.01)$ in SHBG, BT and T in all age groups between 2003 and 2008.

BT= Bioavailable Testosterone; $\mathrm{T}=$ Testosterone; $\mathrm{SHBG}=$ Sexual Hormone Binding Globulin

Figure 2
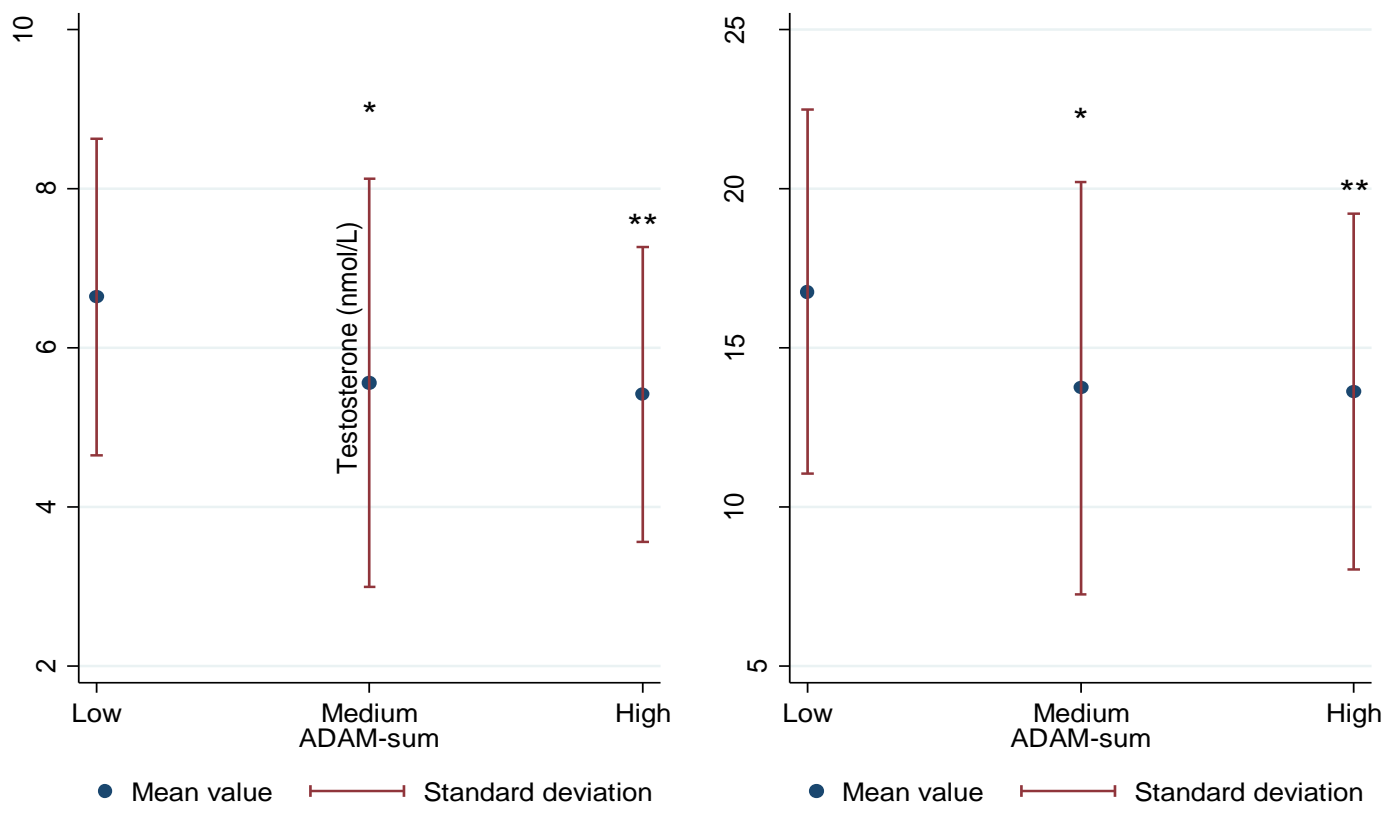

Table I: Demographic data on men answering the specific questions (mean $+/$ - SD or percentage). Answers to every item were not given in all questionnaires.

$\begin{array}{llll}\text { Age group: } & \text { I } & \text { II } & \text { III } \\ & \mathrm{n}=92 & \mathrm{n}=79 & \mathrm{n}=75\end{array}$


BMI $\quad\left(\mathrm{kg} / \mathrm{m}^{2}\right)$

$26.6 \pm 3.7$

$26.3 \pm 3.0$

$26.4 \pm 3.6$

Smoking status:

Never smoked

$28.2 \%(24)$

$35.1 \%(26)$

$45.5 \%(30)$

Former smoker

$55.3 \%(47)$

$48.7 \%(36)$

$47.0 \%(31)$

Smoker

$16.5 \%(14)$

$16.2 \%(12)$

$7.6 \%(5)$

$\underline{\text { Alcohol use* }}$

No alcohol

$6.52 \%(6)$

$5.13 \%(4)$

$21.3 \%(16)$

Some time/month

$38.0 \%$ (35)

$38.5 \%(30)$

$45.3 \%$ (34)

Every week or more

$55.4 \%(51)$

$56.4 \%(44)$

$33.3 \%(25)$

Employ status:

Work fulltime

$45.7 \%$ (42)

$3.8 \%$ (3)

$1.4 \%(1)$

Work part-time

$5.4 \%(5)$

$2.53 \%(2)$

$2.7 \%(2)$

Retired

$32.6 \%(30)$

$92.4 \%(73)$

$96 \%(71)$

Applying for job

$2.2 \%(2)$

Sick-leave

$2.2 \%(2)$

Retired due to disease

$12.0 \%(11)$

$1.3 \%(1)$

Chronic disease

$53.5 \%(46)$

$68.4 \%$ (52)

$64.8 \%(46)$

Daily intake of medicine

$47.7 \%(41)$

$69 \%(49)^{* *}$

$68.7 \%(46)^{* *}$

Exercisehabits:

Golf

$35.1 \%(13)^{* * *}$

$38.1 \%(8)^{* * *}$

$10.5 \%(2)$

Regularly walks

$90.7 \%(78)$

$97.3 \%(71)$

$94.2 \%(65)$

Bicycling

$72.9 \%(35)$

$81.3 \%$ (39)

73.7\% (28)

Tennis, tabletennis,

Badminton or squash

$11.1 \%$ (3)

$6.25 \%(1)$

$5.56 \%(1)$

Jogging

$31.3 \%(10)$

41.7\% (10)

$25.0 \%(5)$

Workout/swimming

$36.7 \%(11)$

$58.3 \%(14)$

$47.8 \%$ (11)

Other sport activities

$32.0 \%(8)$

$58.9 \%(10)$

$58.3 \%$ (14)

* Age group III reported less alcohol intake than the other Age groups $(\mathrm{p}=0.005)$ 
**significantly different from Age-group I ( $\mathrm{p}<0.005)$.

***significantly different from Age-group III ( $\mathrm{p}=0.039)$ 
Table II

Symptoms from the ADAM-questionnaire that is associated with lower T- and BT-concentrations (nmol/L).

Deterioration of

work-performance

$\begin{array}{llll}\text { T } & 13.9 \pm 5.9 & 16.3 \pm 6.4 & \mathrm{p}=0.010 \\ \text { BT } & 5.57 \pm 2.33 & 6.44 \pm 2.14 & \mathrm{p}=0.013\end{array}$

Decreased strength

and/or endurance

$\begin{array}{cccc}\text { T } & 13.9 \pm 6.2 & 16.5 \pm 5.9 & \mathrm{p}=0.0073 \\ \text { BT } & 5.54 \pm 2.33 & 6.57 \pm 2.02 & \mathrm{p}=0.0036\end{array}$

BT= Bioavailable Testosterone; $\mathrm{T}=$ Testosterone 
Table III

Decrease in hormonal concentrations in changes of symptoms reported for the first time 2008 compared to no changes in symptom or relief of symptom since 2003.

Yes 2008, no $2003 \quad$ Unchanged since 2003 or relief

Decrease in libido*

$\begin{array}{llll}\mathrm{BT}(\mathrm{nmol} / \mathrm{L}) & -2.74 \pm 0.57 ; \mathrm{n}=34 & -1.44 \pm 0.27 ; \mathrm{n}=134 & \mathrm{p}=0.032 \\ \mathrm{~T}(\mathrm{nmol} / \mathrm{L}) & -5.01 \pm 1.3 ; \mathrm{n}=34 & -1.79 \pm 0.47 ; \mathrm{n}=136 & \mathrm{p}=0.006\end{array}$

Lack of energy*

$\begin{array}{llll}\mathrm{BT}(\mathrm{nmol} / \mathrm{L}) & -4.05 \pm 1.63 ; \mathrm{n}=13 & -1.51 \pm 0.22 ; \mathrm{n}=159 & \mathrm{p}=0.0044 \\ \mathrm{~T}(\mathrm{nmol} / \mathrm{L}) & -5.13 \pm 2.1 ; \mathrm{n}=15 & -2.26 \pm 0.47 ; \mathrm{n}=159 & \mathrm{~ns}\end{array}$

Decreased strength and/or endurance*

$\begin{array}{llrr}\mathrm{BT}(\mathrm{nmol} / \mathrm{L}) & -2.00 \pm 0.45 ; \mathrm{n}=18 & -1.69 \pm 0.26 ; \mathrm{n}=154 & \mathrm{~ns} \\ \mathrm{~T}(\mathrm{nmol} / \mathrm{L}) & -2.90 \pm 1.13 ; \mathrm{n}=18 & -2.42 \pm 0.50 ; \mathrm{n}=155 & \mathrm{~ns}\end{array}$

Lost in height*

BT $(\mathrm{nmol} / \mathrm{L}) \quad-1.47 \pm 0.49 ; \mathrm{n}=25 \quad-1.73 \pm 0.26 ; \mathrm{n}=148 \quad$ ns

$\mathrm{T}(\mathrm{nmol} / \mathrm{L}) \quad-2.12 \pm 1.3 ; \mathrm{n}=26 \quad-2.52 \pm 0.50 ; \mathrm{n}=149 \quad \mathrm{~ns}$

Decreased enjoyment of life*

$\begin{array}{llll}\mathrm{BT}(\mathrm{nmol} / \mathrm{L}) & -1.36 \pm 0.48 ; \mathrm{n}=16 & -1.65 \pm 0.22 ; \mathrm{n}=156 & \mathrm{~ns} \\ \mathrm{~T}(\mathrm{nmol} / \mathrm{L}) & -2.23 \pm 1.0 ; \mathrm{n}=16 & -2.56 \pm 0.59 ; \mathrm{n}=158 & \mathrm{~ns}\end{array}$

Sadness and/or grumpiness*
$\mathrm{BT}(\mathrm{nmol} / \mathrm{L})$
$-2.12 \pm 0.37 ; n=17$
$-1.67 \pm 0.26 ; n=155$
ns
$\mathrm{T}(\mathrm{nmol} / \mathrm{L})$
$-2.56 \pm 0.66 ; n=17$
$-2.51 \pm 0.51 ; \mathrm{n}=157$
ns

Less strong erections*
BT (nmol/L)
$-3.02 \pm 0.71 ; n=38$
$-1.34 \pm 0.23 ; \mathrm{n}=129$
$\mathrm{p}=0.0036$ 
$\mathrm{T}(\mathrm{nmol} / \mathrm{L})$

$-4.54 \pm 1.23 ; \mathrm{n}=38$

$-1.90 \pm 0.49 ; n=131$

$\mathrm{p}=0.0194$

Deterioration in ability to play sports*

$\mathrm{BT}(\mathrm{nmol} / \mathrm{L})$

$-1.45 \pm 0.68 ; n=17$

$\mathrm{T}(\mathrm{nmol} / \mathrm{L})$

$-1.51 \pm 1.0 ; \mathrm{n}=17$

Falling asleep after dinner*

$\mathrm{BT}(\mathrm{nmol} / \mathrm{L})$

$-1.73 \pm 0.50 ; n=16$

$\mathrm{T}(\mathrm{nmol} / \mathrm{L})$

$-3.30 \pm 1.08 ; n=16$

Deterioration in work performance*

$\mathrm{BT}(\mathrm{nmol} / \mathrm{L})$

$-3.00 \pm 0.76 ; n=23$

$\mathrm{T}(\mathrm{nmol} / \mathrm{L})$

$-5.81 \pm 1.7 ; n=25$

Dry eyes

$\mathrm{BT}(\mathrm{nmol} / \mathrm{L})$

$-1.56 \pm 0.47 ; n=15$

$\mathrm{T}(\mathrm{nmol} / \mathrm{L})$

$-2.85 \pm 1.1 ; \mathrm{n}=15$

Dry and/or fragile skin

$\mathrm{BT}(\mathrm{nmol} / \mathrm{L})$

$-1.80 \pm 0.58 ; n=21$

$\mathrm{T}(\mathrm{nmol} / \mathrm{L})$

$-3.12 \pm 1.7 ; n=21$

Muscular/skeletal pain

BT (nmol/L)

$-1.83 \pm 0.41 ; n=24$

$\mathrm{T}(\mathrm{nmol} / \mathrm{L})$

$-3.10 \pm 0.84 ; \mathrm{n}=24$

Decreased need to shave

$\mathrm{BT}(\mathrm{nmol} / \mathrm{L})$

$-1.36 \pm 0.81 ; n=21$

$\mathrm{T}(\mathrm{nmol} / \mathrm{L})$

$-2.70 \pm 1.6 ; n=21$

Hot flushes:

a few times a week or more
BT (nmol/L)
$+1.23 \pm 3.8 ; \mathrm{n}=4$
$\mathrm{T}(\mathrm{nmol} / \mathrm{L})$
$+1.28 \pm 5.3 ; \mathrm{n}=4$

bother from hot flushes
$-1.76 \pm 0.25 ; n=155$

ns

$-2.62 \pm 0.59 ; n=157$

ns

$$
-1.77 \pm 0.26 ; n=153 \quad n s
$$

$-2.54 \pm 0.51 ; \mathrm{n}=155 \quad$ ns

$$
\begin{array}{ll}
-1.42 \pm 0.21 ; \mathrm{n}=149 & \mathrm{p}=0.0095 \\
-1.98 \pm 0.45 ; \mathrm{n}=149 & \mathrm{p}=0.0035
\end{array}
$$

$-1.87 \pm 0.25 ; n=154 \quad$ ns

$-2.76 \pm 0.48 ; n=156 \quad$ ns

$-1.69 \pm 0.26 ; n=150 \quad n s$

$-2.38 \pm 0.48 ; \mathrm{n}=152 \quad \mathrm{~ns}$

$-1.71 \pm 0.27 ; n=149 \quad$ ns

$-2.42 \pm 0.52 ; n=151 \quad$ ns

$-1.82 \pm 0.25 ; \mathrm{n}=149 \quad \mathrm{~ns}$

$-2.55 \pm 0.49 ; \mathrm{n}=151 \quad \mathrm{~ns}$

BT (nmol/L) 
$\mathrm{T}(\mathrm{nmol} / \mathrm{L})$

$\mathrm{BT}=$ Bioavailable Testosterone; $\mathrm{T}=$ Testosterone

BT diff $(\mathrm{nmol} / \mathrm{L})=$ decrease in BT concentration between 2003 and 2008

*A question included in the ADAM-questionnaire 